\title{
Health-related quality of life in patients treated with atypical antipsychotics
}

\author{
Juliana L. de Almeida, ${ }^{1}$ Isabella de Figueiredo Zuppo, ${ }^{1}$ iD Saulo Castel, ${ }^{2}$ Edna A. Reis, ${ }^{3}$ \\ Helian N. de Oliveira, ${ }^{4}$ Cristina M. Ruas ${ }^{5}$ (iD
}

${ }^{1}$ Programa de Pós-Graduação em Medicamentos e Assistência Farmacêutica, Universidade Federal de Minas Gerais (UFMG), Belo Horizonte, MG, Brazil. ${ }^{2}$ Department of Psychiatry, University of Toronto, Toronto, ON, Canada. ${ }^{3}$ Departamento de Estatística, UFMG, Belo Horizonte, MG, Brazil. ${ }^{4}$ Departamento de Medicina Preventiva e Social, UFMG, Belo Horizonte, MG, Brazil. ${ }^{5}$ Departamento de Farmácia Social, UFMG, Belo Horizonte, MG, Brazil.

\begin{abstract}
Objective: To assess health-related quality of life and associated factors in patients treated with atypical antipsychotics, as well as to determine utility values using the EuroQol-5D-3L instrument. Methods: A cross-sectional study was conducted at a state-run pharmacy in the Brazilian National Health System. Individuals were included if they were using a single atypical antipsychotic and completed the EuroQol-5D-3L. Sociodemographic, behavioral, and clinical data were collected. The dependent variable was the EuroQol-5D-3L utility score. Associations between the independent variables and the dependent variable were analyzed in a multiple linear regression model.

Results: A total of 394 patients were included, and their mean utility score was $0.664 \pm 0.232$. Patients treated with clozapine had the highest mean score $(0.762$ [0.202]), followed by olanzapine $(0.687$ [0.230]), risperidone (0.630 [0.252]), ziprasidone (0.622 [0.234]), and quetiapine (0.620 [0.243]). The following variables were related to higher utility scores: income, employment, clozapine use, no illicit psychoactive substance use, no suicide attempts, and no comorbidities.

Conclusion: Evaluating health-related quality of life differences in the available atypical antipsychotics can facilitate the choice of treatment, improve health outcomes, and ensure rational prescriptions.
\end{abstract}

Keywords: Quality of life; antipsychotic agents; mental disorders

\section{Introduction}

Quality of life (QoL) is a multidimensional concept that was first considered a complement to traditional concepts of health and functionality. An ideal and complete measurement of health would assess an individual's physical, functional, social, and psychological health. ${ }^{1}$ This concept has become more prominent in health care as new technologies have extended life, sometimes at the expense of QoL, or have improved QoL without extending life. Therefore, measuring outcomes such as death rates and life expectancy alone is no longer sufficient, and the need to assess health-related QoL (HRQoL) has emerged. ${ }^{2}$ $\mathrm{HRQ}$ L is a measure of perceived physical and mental health, including functional status, social support, and socioeconomic status, as part of the multidimensional construct of health status. ${ }^{3}$

The practice of evaluating $\mathrm{HRQ}$ oL in chronic diseases has become well established, and it has also gained prominence in severe mental illness since the deinstitutionalization and reintegration of psychiatric patients in the community. ${ }^{4}$ Such an evaluation is essential for these

Correspondence: Cristina M. Ruas, Departamento de Farmácia Social, Universidade Federal de Minas Gerais, Av. Antônio Carlos, 6627, CEP 31310-430, Belo Horizonte, MG, Brazil.

E-mail: crisruasufmg@gmail.com

Submitted Oct 01 2019, accepted Feb 07 2020, Epub Jun 122020. patients because it measures not only the direct benefits (i.e., reduced psychotic symptoms) of antipsychotics, ${ }^{5}$ but other related factors in their lives. ${ }^{6}$ New antipsychotic agents, although more effective, also have a range of adverse effects ${ }^{7,8}$ that could negatively affect health outcomes such as QoL. Since the focus of atypical antipsychotic treatment is not only symptom reduction, but improvement of QoL, ${ }^{8}$ it is important to evaluate this outcome.

Different instruments for measuring HRQoL have been developed and/or validated in Brazil, ${ }^{9}$ including the Euro Qol-5D-3L (EQ-5D-3L). ${ }^{10}$ The EQ-5D-3L is a generic HR QoL measurement instrument that is divided into two stages: a five-dimension descriptive system and a visual analog scale. The EQ-5D-3L's descriptive system includes five dimensions: mobility, self-care, usual activities, pain/discomfort, and anxiety/depression. Each of the five dimensions has three levels: no problems, some problems, and extreme problems. A five-digit number, generated from the individual's self-assessment in the five dimensions, describes the respondent's health status, and this number is referred to as the utility score. ${ }^{10}$
How to cite this article: de Almeida JL, Zuppo IF, Castel S, Reis $\mathrm{EA}$, de Oliveira HN, Ruas CM. Health-related quality of life in patients treated with atypical antipsychotics. Braz J Psychiatry. 2020;42:599607. http://dx.doi.org/10.1590/1516-4446-2019-0739 
The Brazilian Unified Health System provides drug treatments, including atypical antipsychotics for patients with mental disorders. ${ }^{11,12}$ The use of such drugs must comply with criteria established in the Brazilian Ministry of Health's Clinical Protocol and Therapeutic Guidelines for rational drug therapy. ${ }^{11-13}$

The therapeutic guidelines indicate atypical antipsychotics for schizophrenia, schizoaffective disorder, and type 1 bipolar disorder. For schizophrenia and schizoaffective disorder, the available atypical antipsychotics include clozapine, risperidone, ziprasidone, quetiapine, and olanzapine. Except for clozapine, there is no preferred order of treatment with these atypical antipsychotics. ${ }^{11,12}$ For bipolar disorder type I, the protocol describes a sequence of antipsychotics for mania treatment: risperidone, followed by olanzapine, haloperidol, and quetiapine, if necessary. ${ }^{13}$ Clozapine is indicated in the three protocols when other antipsychotics are ineffective..$^{11-13}$

HRQoL is a useful tool in psychiatry since it evaluates the impact of mental illness and the possible benefits of therapeutic interventions. ${ }^{14}$ This study aims to evaluate HRQoL and associated factors in patients with mental disorders who are being treated with atypical antipsychotics, as well to calculate their utility scores. The results of this study could lead to further research and could help determine which drugs have the greatest clinical benefits for QoL in people with psychotic disorders.

\section{Methods}

This study is part of the Schizophrenia Economics and Effectiveness Assessment (SCHEEA) project ${ }^{15}$ of the Universidade Federal de Minas Gerais, Brazil. In this project, patients were recruited from a state pharmacy of the Specialized Component of Pharmaceutical Service (Componente Especializado da Assistência Farmacêutica [CEAF]) in Belo Horizonte, state of Minas Gerais. Individuals using only one atypical antipsychotic (clozapine, olanzapine, ziprasidone, quetiapine, or risperidone) and who completed the QoL questionnaire (EQ-5D-3L) were eligible for inclusion. Before their antipsychotic drugs were dispensed, the patients were invited to participate in the study, and those who agreed to participate were referred for face-to-face interviews. Along with the HRQoL assessment, a structured questionnaire was used to collect data on sociodemographics, medication use, and behavioral and clinical variables. The study was conducted between September 2017 and March 2018.

The sample size was calculated to compare HRQoL among patients treated with different drugs. A mean of 5,800 patients used the selected drugs at the CEAF pharmacy per month (according to the means from June and July 2017). The primary outcome in this study was the EQ-5D-3L utility score, which ranges from 0 to 1. Since 0 is related to death and 1 to better health, the amplitude was considered 0.9 (range 0.05 to 0.95 ). Considering 6 standard deviations (SD) (with normal distribution), the sample SD was $0.15(0.9 / 6)$. We expected to detect a minimum difference between the mean utility values between treatments of at least 0.1 , with a $5 \%$ significance level and $90 \%$ power. Using analysis of variance
(ANOVA), we calculated $n=71$ patients per treatment type.

HRQoL was assessed using the EQ-5D-3L, an instrument developed by the EuroQol Group that has been validated for Brazilian Portuguese. ${ }^{16}$ The EQ-5D-3L is a generic questionnaire that assesses QoL by identifying 243 possible states of health based on five dimensions: mobility, self-care, usual activities, pain/discomfort, and anxiety/depression. Three alternatives exist for each dimension: no problems, some problems, and severe problems. The possible health states range from 11111 (no problems in any dimension) to 33333 (severe problems in all dimensions), and each state has a corresponding utility score (registration ID: L-29510). ${ }^{17}$

We compared the percentage of patients in our sample who had moderate or extreme problems in the EQ-5D-3L dimensions with scores from the general population of the state of Minas Gerais found by Andrade \& Noronha. ${ }^{10}$ These authors interviewed 3,363 individuals from different locations, which were representative of the entire geographic area of the state. Comparing these two samples highlighted the differences between them.

In our study, the dependent variable was the utility score for patients treated with atypical antipsychotics. The independent variables were: sociodemographic characteristics (gender, age, marital status, education level, employment status, and race),${ }^{18-21}$ clinical characteristics (comorbidities such as hypertension, diabetes, heart disease, human immunodeficiency virus, thyroid dysfunction, respiratory diseases, chronic liver diseases, and chronic kidney diseases), ${ }^{22}$ and behavioral characteristics (psychoactive substance use, suicide attempts, and use of mental health services). ${ }^{23,24}$

The statistical analysis included absolute and relative frequency for qualitative variables and measures of central tendency (mean and median) and variability (SD and coefficient of variation) for quantitative variables. A normality test (Kolmogorov-Smirnov) was used to verify Gaussian distribution. For nonparametric distribution (according to the Mann Whitney $U$ and Kruskal-Wallis test), ANOVA was used to verify differences in mean utility scores among treatment groups. Dunn's test was used for multiple comparisons.

Associations among independent variables (gender, age, marital status, education level, and employment status), clinical variables (comorbid diseases), and $\mathrm{HRQ}$ oL (utility scores) were evaluated in univariate ANOVA with a significance level $<10 \%$. The identified variables were included in a multiple linear regression model with a significance level of 0.05 . Statistical analyses were performed in SPSS version 22.0.

\section{Ethics statement}

Research personnel at the recruitment sites provided information about the study protocol. All individuals who expressed interest in participating received a full explanation of the study procedures and provided written informed consent. The study protocol and the interview procedures were approved by the relevant UFMG ethics committee (CAAE 57420616.9.0000.5149). 


\section{Results}

The majority of the 394 interviewed patients were men $(54.8 \%)$, except in the ziprasidone and quetiapine groups. The predominant age range was $30-59$ years $(80.5 \%)$. The clozapine group had the highest percentage of young adults $(32.3 \%)$, while the quetiapine group had the highest percentage of older adults (19.4\%) (Table 1).

Of the patients in our sample, $32.2 \%$ had completed some higher education and $16.5 \%$ were employed at the time of the interview. The risperidone group had the lowest percentages among all groups, with $11.1 \%$ having completed some higher education and $8.9 \%$ currently employed. Concerning marital status, $77.7 \%$ of the patients did not have a partner, and the quetiapine group had the highest percentage of patients with a partner (27.8\%). Regarding self-reported race, $55.1 \%$ of were mixed race or Afro-Brazilian. The ziprasidone group had the highest percentage of Afro-Brazilians and individuals of mixed race $(62 \%)$, while the quetiapine group had the highest percentage of Caucasians and Asians (47.2\%).

The clinical and behavioral characteristics of patients using atypical antipsychotics are shown in Table 2. In total, $47.5 \%$ reported no comorbidities, $30.7 \%$ reported one, and $19.5 \%$ reported two or more. The olanzapine group had the highest percentage who reported no comorbidities $(50.4 \%)$, while the risperidone group had the highest percentage of those who reported two or more associated diseases $(24.4 \%)$. A total of $34.5 \%$ of the patients reported having attempted suicide. The risperidone group had the highest percentage of patients with no suicide attempts $(77.8 \%)$, while the ziprasidone group had the highest percentage of patients who had attempted it three or more times $(28.2 \%)$. A total of $21.8 \%$ of the patients reported having used illicit psychoactive substances at some point in their lives. The ziprasidone group had the highest percentage of patients who had never used them $(83.1 \%)$, while the risperidone group had the highest percentage of those who had used three or more types (8.7\%). Data was collected on the use of psychosocial care centers (Centros de Atenção Psicossocial [CAPS]) and mental health referral centers (Centros de Referência em Saúde Mental [CERSAM]), with 53.3\% of the patients reporting that they had used them. The quetiapine group had the highest percentage of patients who reported using all types of mental health services.

Responses for each EQ-5D-3L dimension differed according to antipsychotic type (Table 3 ). The olanzapine,

Table 1 Sociodemographic characteristics of patients treated with atypical antipsychotics provided by the CEAF pharmacy in the state of Minas Gerais, 2017-2018

\begin{tabular}{|c|c|c|c|c|c|c|}
\hline & Clozapine & Olanzapine & Quetiapine & Risperidone & Ziprasidone & Global \\
\hline \multicolumn{7}{|l|}{ Gender } \\
\hline Female & $18(27.7)$ & $53(37.6)$ & $43(59.7)$ & 15 (33.3) & $49(69.0)$ & $178(45.2)$ \\
\hline Male & 47 (72.3) & $88(62.4)$ & $29(40.3)$ & $30(66.7)$ & $22(31.0)$ & $216(54.8)$ \\
\hline \multicolumn{7}{|l|}{ Age, years } \\
\hline $18-29$ & $2(3.1)$ & $8(5.7)$ & $3(4.2)$ & $7(15.6)$ & $3(4.2)$ & $23(5.8)$ \\
\hline $30-39$ & $19(29.2)$ & $25(17.7)$ & $12(16.7)$ & $10(22.2)$ & $17(23.9)$ & $83(21.1)$ \\
\hline $40-49$ & 22 (33.8) & $42(29.1)$ & $23(31.9)$ & $14(31.1)$ & $21(29.6)$ & $121(30.7)$ \\
\hline $50-59$ & $17(26.2)$ & 47 (33.3) & $20(27.8)$ & $9(20.0)$ & $20(28.2)$ & $113(28.7)$ \\
\hline$>60$ & $5(7.7)$ & $19(13.5)$ & $14(19.4)$ & $5(11.1)$ & $10(14.1)$ & $53(13.5)$ \\
\hline \multicolumn{7}{|l|}{ Education } \\
\hline Primary education & $25(38.5)$ & $40(28.3)$ & $16(22.2)$ & $20(44.4)$ & $14(19.7)$ & $115(29.2)$ \\
\hline Secondary education & $28(43.1)$ & $44(31.2)$ & $29(40.3)$ & $20(44.4)$ & $31(43.7)$ & $152(38.6)$ \\
\hline Higher education & $12(18.5)$ & $57(40.4)$ & $27(37.5)$ & $5(11.1)$ & $26(36.6)$ & $127(32.2)$ \\
\hline \multicolumn{7}{|l|}{ Labor activity } \\
\hline Working & $11(16.9)$ & $30(21.3)$ & $10(13.9)$ & $4(8.9)$ & $11(15.5)$ & $65(16.5)$ \\
\hline Unemployed/unplaced/retiree & $54(83.1)$ & $111(78.7)$ & $62(86.1)$ & $41(91.1)$ & $58(81.7)$ & $329(83.5)$ \\
\hline \multicolumn{7}{|l|}{ Marital status } \\
\hline With a partner & $13(19.12)$ & $28(19.8)$ & $20(27.8)$ & $10(22.2)$ & $18(25.4)$ & $88(22.3)$ \\
\hline Without a partner & $52(80.88)$ & $113(80.1)$ & $52(72.2)$ & $35(77.8)$ & $53(74.6)$ & $306(77.7)$ \\
\hline \multicolumn{7}{|l|}{ Family income } \\
\hline Up to $4 x$ the minimum salary & $42(64.6)$ & $89(63.1)$ & $52(72.2)$ & $34(75.6)$ & $51(71.8)$ & $368(68.0)$ \\
\hline 4 to $8 x$ & $4(6.2)$ & $20(14.2)$ & $5(6.9)$ & $2(4.4)$ & $8(11.3)$ & $39(9.9)$ \\
\hline More than $8 x$ & $5(7.7)$ & $8(5.7)$ & $3(4.2)$ & $1(2.2)$ & $4(5.6)$ & $21(5.3)$ \\
\hline Don’t know & $14(21.5)$ & $17(17.0)$ & $12(16.7)$ & $8(17.8)$ & $8(11.3)$ & $66(16.8)$ \\
\hline \multicolumn{7}{|l|}{ Race } \\
\hline Caucasian/Asian & $24(36.9)$ & $65(46.1)$ & $34(47.2)$ & $14(31.1)$ & $25(35.2)$ & $162(41.1)$ \\
\hline Mixed/Afro-Brazilian & $40(61.5)$ & $72(51.1)$ & $34(47.2)$ & $27(60.0)$ & $44(62.0)$ & $217(55.1)$ \\
\hline Did not answer & $1(1.5)$ & $4(2.8)$ & $4(5.6)$ & $4(8.9)$ & $1(1.4)$ & $15(3.8)$ \\
\hline Total & $65(100.0)$ & $141(100.0)$ & $72(100.0)$ & $45(100.0)$ & $71(100.0)$ & $394(100.0)$ \\
\hline
\end{tabular}

Data presented as $\mathrm{n}(\%)$.

$\mathrm{CEAF}=$ Componente Especializado da Assistência Farmacêutica (Specialized Component of Pharmaceutical Service). 
Table 2 Clinical and behavioral characteristics of patients treated with atypical antipsychotics provided by the CEAF pharmacy in the state of Minas Gerais, 2017-2018 ${ }^{15}$

\begin{tabular}{|c|c|c|c|c|c|c|}
\hline & Clozapine & Olanzapine & Quetiapine & Risperidone & Ziprasidone & Global \\
\hline \multicolumn{7}{|l|}{ Other diseases } \\
\hline None & $32(49.2)$ & $71(50.4)$ & $29(40.3)$ & $21(46.7)$ & $34(47.9)$ & $187(47.5)$ \\
\hline One & $22(33.8)$ & $34(24.1)$ & $26(36.1)$ & $13(28.9)$ & $26(36.6)$ & $121(30.7)$ \\
\hline Two or more & $10(15.4)$ & $29(20.6)$ & $16(22.2)$ & $11(24.4)$ & $11(15.5)$ & $77(19.5)$ \\
\hline Did not answer & $1(1.5)$ & $7(5.0)$ & $1(1.4)$ & - & - & $9(2.3)$ \\
\hline \multicolumn{7}{|l|}{ Suicide attempts } \\
\hline None & $46(70.8)$ & $94(66.7)$ & $45(62.5)$ & $35(77.8)$ & $38(53.5)$ & $258(65.5)$ \\
\hline Once & $4(6.2)$ & $21(14.9)$ & $11(15.3)$ & $2(2.4)$ & $7(9.9)$ & $45(11.4)$ \\
\hline Twice & $5(7.7)$ & $5(3.5)$ & $5(6.9)$ & $4(8.9)$ & $6(8.5)$ & $25(6.3)$ \\
\hline Three or more times & $10(15.4)$ & $21(14.9)$ & $11(15.3)$ & $4(8.9)$ & $20(28.2)$ & $66(16.8)$ \\
\hline \multicolumn{7}{|l|}{ Psychoactive substance use } \\
\hline None & $48(73.82)$ & $107(75.9)$ & $49(68.1)$ & $35(78.2)$ & $59(83.1)$ & $298(75.6)$ \\
\hline One type & $8(12.3)$ & $12(8.5)$ & $11(15.3)$ & $5(10.9)$ & $2(2.8)$ & $38(9.6)$ \\
\hline Two types & $4(6.2)$ & $6(4.3)$ & $6(8.3)$ & $1(2.2)$ & $3(4.2)$ & $20(5.1)$ \\
\hline Three or more types & $3(4.6)$ & $10(7.1)$ & $5(7.0)$ & $4(8.7)$ & $6(8.4)$ & $28(7.1)$ \\
\hline Did not answer & $2(3.1)$ & $6(4.3)$ & $1(1.4)$ & - & $1(1.4)$ & $10(2.5)$ \\
\hline \multicolumn{7}{|l|}{ Frequency of CAPS/CERSAM use } \\
\hline None & $28(43.1)$ & $71(50.4)$ & $30(41.7)$ & $22(48.9)$ & $33(46.5)$ & $184(46.7)$ \\
\hline Visits or group activities & 17 (26.2) & $33(23.4)$ & $19(26.4)$ & $13(28.9)$ & $19(26.8)$ & $101(25.6)$ \\
\hline Stays all day & $11(16.9)$ & $22(15.6)$ & $13(18.1)$ & $8(17.8)$ & $13(18.3)$ & $67(17.0)$ \\
\hline Overnight stays or hospitalization & $9(13.8)$ & $15(10.6)$ & $10(13.9)$ & $2(4.4)$ & $6(8.5)$ & $42(10.7)$ \\
\hline Total & $65(100.0)$ & $141(100.0)$ & $72(100.0)$ & $45(100.0)$ & $71(100.0)$ & $394(100.0)$ \\
\hline
\end{tabular}

Data presented as $\mathrm{n}(\%)$.

CAPS = Centro de Atenção Psicossocial (phychosocial care center); CEAF = Componente Especializado da Assistência Farmacêutica (Specialized Component of Pharmaceutical Service); CERSAM = Centro de Referência em Saúde Mental (mental health referral center).

Table 3 EuroQol-5D-3L dimension scores of patients treated with atypical antipsychotics provided by the CEAF pharmacy in the state of Minas Gerais, 2017-2018

\begin{tabular}{|c|c|c|c|c|c|c|}
\hline Dimensions & Clozapine & Olanzapine & Quetiapine & Risperidone & Ziprasidone & Global \\
\hline \multicolumn{7}{|l|}{ Mobility } \\
\hline 1 & $51(78.5)$ & $108(76.6)$ & $46(63.9)$ & $29(65.9)$ & $50(70.4)$ & $284(72.3)$ \\
\hline 2 & $13(20.0)$ & $30(21.3)$ & $21(29.2)$ & $12(27.3)$ & $17(23.9)$ & $93(23.7)$ \\
\hline 3 & $1(1.5)$ & $3(2.1)$ & $5(6.9)$ & $3(6.8)$ & $4(5.6)$ & $16(4.1)$ \\
\hline \multicolumn{7}{|l|}{ Self-care } \\
\hline 1 & 60 (92.3) & $121(85.8)$ & $55(76.4)$ & $34(77.3)$ & $58(81.7)$ & $328(83.5)$ \\
\hline 2 & $4(6.2)$ & $15(10.6)$ & $17(23.6)$ & $8(18.2)$ & $12(16.9)$ & $56(14.2)$ \\
\hline 3 & $1(1.5)$ & $5(3.5)$ & $0(0)$ & $2(4.5)$ & $1(1.4)$ & $9(2.3)$ \\
\hline \multicolumn{7}{|c|}{ Usual activities } \\
\hline 1 & $43(66.2)$ & $82(58.2)$ & $34(47.2)$ & $23(52.3)$ & $29(40.8)$ & $221(53.7)$ \\
\hline 2 & $17(26.2)$ & $33(23.4)$ & $26(36.1)$ & $16(36.4)$ & $30(42.3)$ & $122(31.0)$ \\
\hline 3 & $5(7.7)$ & $26(18.4)$ & $12(16.7)$ & $5(11.4)$ & 12 (16.9) & $60(16.3)$ \\
\hline \multicolumn{7}{|c|}{ Pain/discomfort } \\
\hline 1 & 47 (72.3) & $89(63.1)$ & $36(50.0)$ & $23(52.3)$ & $38(53.5)$ & 233 (59.3) \\
\hline 2 & $17(26.2)$ & $30(21.3)$ & $26(36.1)$ & $15(34.1)$ & $22(31.0)$ & $110(28.0)$ \\
\hline 3 & $1(1.5)$ & $22(15.6)$ & $10(13.9)$ & $6(13.6)$ & $11(15.5)$ & $50(12.7)$ \\
\hline \multicolumn{7}{|c|}{ Anxiety/depression } \\
\hline 1 & $26(40.0)$ & $46(32.6)$ & $36(50.0)$ & $12(27.3)$ & $16(22.5)$ & $119(30.3)$ \\
\hline 2 & $30(46.2)$ & $62(44.0)$ & $26(36.1)$ & $16(36.4)$ & $27(38.0)$ & $165(42.0)$ \\
\hline 3 & $9(13.8)$ & $32(22.7)$ & $10(13.9)$ & $16(36.4)$ & $28(39.4)$ & $109(27.7)$ \\
\hline Total & $65(100.0)$ & $141(100.0)$ & $72(100.0)$ & $45(100.0)$ & $71(100.0)$ & $394(100.0)$ \\
\hline
\end{tabular}

Data presented as $\mathrm{n}(\%)$.

$\mathrm{CEAF}=$ Componente Especializado da Assistência Farmacêutica (Specialized Component of Pharmaceutical Service).

1 = no problems; 2 = some problems; 3 = extreme problems. 


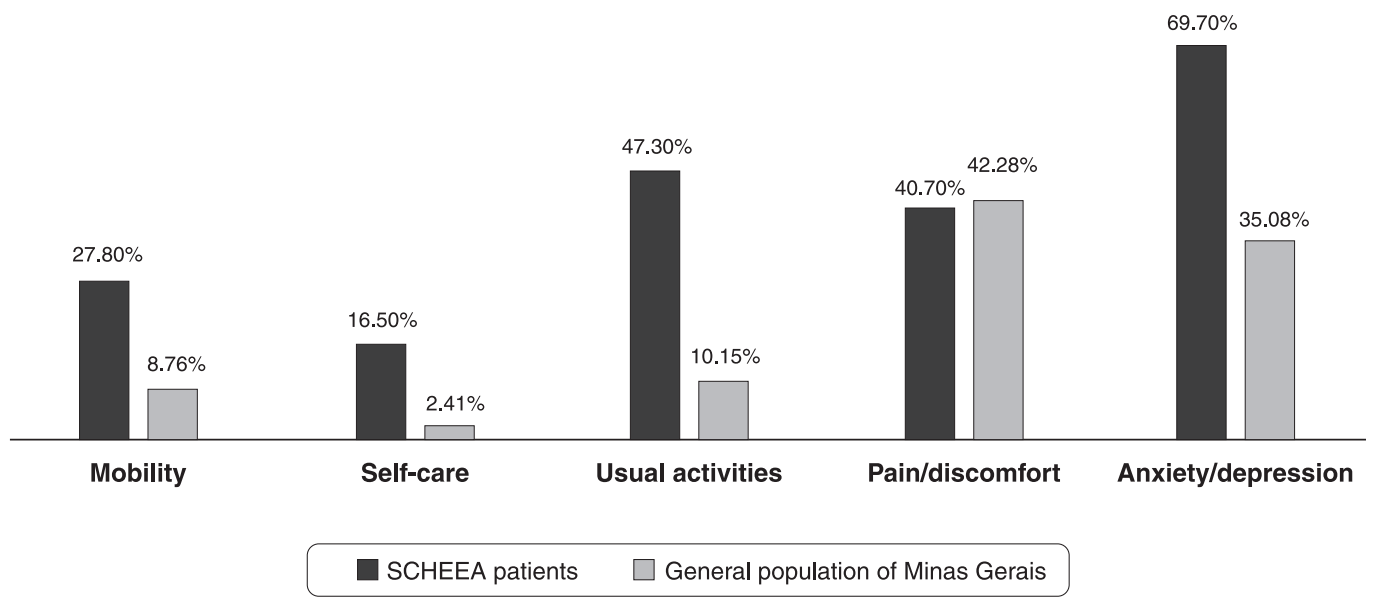

Figure 1 A comparison of people who reported problems in each dimension of the EuroQol-5D-3L: patients treated with atypical antipsychotics provided by the Specialized Component of Pharmaceutical Service (Componente Especializado da Assistência Farmacêutica [CEAF]) pharmacy vs. individuals from the general population of the state of Minas Gerais. SCHEEA = Schizophrenia Economics and Effectiveness Assessment project.

quetiapine, risperidone, and ziprasidone groups had the highest proportions who reported "extreme problems." The quetiapine (6.9\%) and risperidone (6.8\%) groups reported the most problems in the mobility dimension. The risperidone group (4.5\%) reported the most problems in the self-care dimension. The olanzapine group (18.4\%) reported the most problems in the usual activities dimension. The olanzapine (15.6\%) and ziprasidone (15.5\%) groups reported the most problems in the pain/discomfort dimension. Finally, the risperidone (36.4\%) and ziprasidone $(39.4 \%)$ groups reported the most problems in the anxiety and depression dimension. The clozapine group had the most patients who reported "no problems" in four of the five dimensions (mobility, self-care, usual activities, and pain/discomfort), and the quetiapine group was the most frequent to report "no problems" in the depression/ anxiety dimension.

Figure 1 compares patients from the SCHEEA project with individuals from the statewide sample who reported problems in the EQ-5D-3L dimensions. SCHEEA project patients had the highest percentages in every dimension except pain/discomfort, in which both groups were similar.

The participants' utility scores were calculated according to their EQ-5D-3L responses. The mean score was $0.664 \pm 0.232$. The clozapine group had the highest mean score $(0.762 \pm 0.202)$, followed by the olanzapine group $(0.687 \pm 0.230)$ and the risperidone group $(0.630 \pm 0.252)$. The lowest scoring groups were ziprasidone $(0.622 \pm$ $0.234)$ and quetiapine $(0.620 \pm 0.243)$.

Table 4 shows the relationship between sociodemographic, clinical, and behavioral variables and utility scores. Gender, education, income, employment, and race were significantly associated with utility score. All other clinical and behavioral variables were also significant (suicide attempts, psychoactive substance use, use of mental health services - CAPS/CERSAM, and comorbid diseases). Medication type was also significantly associated with utility score.

A multiple linear regression model was used to determine which variables were associated with higher utility scores (Table 5). The final model contained variables whose significance level was $5 \%$ or less. The variables that remained in the model were: income, employment, comorbid diseases, psychoactive substance use, suicide attempts, and medication type.

According to the model, the mean utility score of patients who earned more than eight times the federal minimum salary was 0.128 units higher than that of patients who earned less than four times the minimum salary. The mean score of employed patients was 0.122 units higher than that of unemployed or retired patients. The mean score of patients without comorbidities was 0.069 units higher than that of patients with comorbidities. The mean score of those who had never used illicit psychoactive substances was 0.102 units higher than that former or current users. The mean score of those who had not attempted suicide was 0.157 units higher than that of those who had. Moreover, the mean score of clozapine users was higher than all other medication types: $0.113,0.110,0.113$, and 0.070 units higher than ziprasidone, risperidone, quetiapine, and olanzapine, respectively.

\section{Discussion}

Our sample was predominantly male, aged 30-59 years, unemployed, without a partner, and with a low education level, which corroborates other research. ${ }^{21,25}$ Although most of the patients are in the economically active age group, they are largely unemployed ${ }^{21}$ due to mental illness. Mental disorders affect individuals at an early age, before they have finished school. Due to the disease, stigma or both, their school attendance is irregular, reducing the possibility of employment. They are also unable to achieve stable relationships. ${ }^{19,21}$

Most SCHEEA antipsychotic users self-reported their race as Afro-Brazilian or mixed (55.1\%). Studies have found that blacks are three times more likely than whites to use psychosis services. ${ }^{20}$

More than $20 \%$ of the participants have used illicit psychoactive substances. The use of these substances 
Table 4 Utility scores stratified according to patient characteristics in a sample of patients treated with atypical antipsychotics provided by the CEAF pharmacy in the state of Minas Gerais, $2017-2018^{15}$

\begin{tabular}{|c|c|c|c|}
\hline Variables & Mean utility (SD) & Median (1st quartile; 3rd quartile) & $p$-value \\
\hline $\begin{array}{l}\text { Gender } \\
\text { Male } \\
\text { Female }\end{array}$ & $\begin{array}{l}0.693(0.222) \\
0.639(0.248)\end{array}$ & $\begin{array}{l}0.704(0.578 ; 0.801) \\
0.663(0.519 ; 0.801)\end{array}$ & 0.070 \\
\hline $\begin{array}{c}\text { Age, years } \\
18-29 \\
29-39 \\
39-49 \\
49-59 \\
\text { Over } 60\end{array}$ & $\begin{array}{l}0.674(0.190) \\
0.668(0.307) \\
0.694(0.213) \\
0.639(0.223) \\
0.677(0.198)\end{array}$ & $\begin{array}{l}0.704(0.588 ; 0.801) \\
0.736(0.536 ; 1.000) \\
0.691(0.572 ; 0.801) \\
0.673(0.519 ; 0.786) \\
0.731(0.494 ; 0.794)\end{array}$ & 0.339 \\
\hline $\begin{array}{l}\text { Marital status } \\
\text { Single/divorced/widowed } \\
\text { Married }\end{array}$ & $\begin{array}{l}0.671(0.236) \\
0.661(0.236)\end{array}$ & $\begin{array}{l}0.691(0.572 ; 0.801) \\
0.681(0.503 ; 0.801)\end{array}$ & 0.564 \\
\hline $\begin{array}{l}\text { Education } \\
\text { Primary education* } \\
\text { Secondary education } \\
\text { Higher education }\end{array}$ & $\begin{array}{l}0651(0.227) \\
0.657(0.245) \\
0.712(0.207)\end{array}$ & $\begin{array}{l}0.662(0.519 ; 0.797) \\
0.704(0.519 ; 0.801) \\
0.736(0.616 ; 0.801)\end{array}$ & 0.061 \\
\hline $\begin{array}{l}\text { Income } \\
\text { Up to } 4 x \text { the minimum salary } \\
\text { From } 4 \text { to } 8 x \\
\text { More than } 8 x\end{array}$ & $\begin{array}{l}0.650(0.228) \\
0.741(0.179) \\
0.837(0.179)\end{array}$ & $\begin{array}{l}0.659(0.519 ; 0.801) \\
0.736(0.624 ; 0.801) \\
0.801(0.704 ; 1.000)\end{array}$ & 0.000 \\
\hline $\begin{array}{l}\text { Employment } \\
\text { Unemployed/retired } \\
\text { Employed }\end{array}$ & $\begin{array}{l}0.645(0.238) \\
0.798(0.176)\end{array}$ & $\begin{array}{l}0.666(0.519 ; 0.801) \\
0.801(0.686 ; 1.000)\end{array}$ & 0.000 \\
\hline $\begin{array}{l}\text { Suicide attempts } \\
\text { None } \\
\text { One } \\
\text { Two } \\
\text { Three or more }\end{array}$ & $\begin{array}{l}0.722(0.207) \\
0.591(0.263) \\
0.584(0.200) \\
0.549(0.266)\end{array}$ & $\begin{array}{l}0.736(0.619 ; 0.801) \\
0.637(0.451 ; 0.756) \\
0.592(0.463 ; 0.704) \\
0.539(0.405 ; 0.754)\end{array}$ & 0.000 \\
\hline $\begin{array}{l}\text { Comorbid diseases } \\
\text { None } \\
\text { One disease } \\
\text { Two or more disease }\end{array}$ & $\begin{array}{l}0.700(0.229) \\
0.656(0.230) \\
0.606(0.227)\end{array}$ & $\begin{array}{l}0.704(0.583 ; 0.801) \\
0.691(0.520 ; 0.801) \\
0.626(0.456 ; 0.786)\end{array}$ & 0.005 \\
\hline $\begin{array}{l}\text { Race } \\
\text { Caucasian/Asian } \\
\text { Mixed/Afro-Brazilian }\end{array}$ & $\begin{array}{l}0.700(0.205) \\
0.645(0.256)\end{array}$ & $\begin{array}{l}0.704(0.594 ; 0.801) \\
0.681(0.503 ; 0.801)\end{array}$ & 0.063 \\
\hline $\begin{array}{l}\text { Psychoactive substance use } \\
\text { Never used } \\
\text { Former of current user }\end{array}$ & $\begin{array}{l}0.677(0.228) \\
0.664(0.212)\end{array}$ & $\begin{array}{l}0.704(0.571 ; 0.801) \\
0.692(0.520 ; 0.801)\end{array}$ & 0.072 \\
\hline $\begin{array}{l}\text { CAPS/ CERSAM use } \\
\text { None } \\
\text { Group activities/visits } \\
\text { All day stays" } \\
\text { Overnight/hospitalization (> } 24 \mathrm{~h} \text { ) }\end{array}$ & $\begin{array}{l}0.703(0.219) \\
0.658(0.228) \\
0.618(0.276) \\
0.626(0.240)\end{array}$ & $\begin{array}{l}0.704(0.592 ; 0.801) \\
0.666(0.571 ; 0.801) \\
0.642(0.452 ; 0.801) \\
0.675(0.458 ; 0.790)\end{array}$ & 0.068 \\
\hline $\begin{array}{l}\text { Medication } \\
\text { Clozapine } \\
\text { Olanzapine } \\
\text { Quetiapine } \\
\text { Risperidone } \\
\text { Ziprasidone }\end{array}$ & $\begin{array}{l}0.762(0.202) \\
0.687(0.230) \\
0.620(0.243) \\
0.630(0.252) \\
0.622(0.234)\end{array}$ & $\begin{array}{l}0.786(0.662 ; 1.000) \\
0.704(0.572 ; 0.801) \\
0.659(0.478 ; 0.786) \\
0.640(0.539 ; 0.763) \\
0.639(0.491 ; 0.786)\end{array}$ & 0.001 \\
\hline
\end{tabular}

For variables with two categories, the Mann Whitney $U$ test was performed, for three or more, the Kruskal-Wallis test was performed followed by the Dunn test.

CAPS = Centro de Atenção Psicossocial (phychosocial care center); CEAF = Componente Especializado da Assistência Farmacêutica (Specialized Component of Pharmaceutical Service); CERSAM = Centro de Referência em Saúde Mental (mental health referral center); $\mathrm{SD}=$ standard deviation.

* Significant difference compared to patients with a higher education level.

Significant difference compared to patients whose income is four to eight times the minimum salary and patients whose income is over eight times the minimum salary.

\# Significant difference compared to patients who have not attempted suicide.

$\S$ Significant difference compared to patients with no comorbid disease.

"Significant difference compared to patients not do not use CAPS/CERSAM services.

'Significant difference compared to the quetiapine, risperidone, and ziprasidone groups. 
Table 5 Multiple linear regression of variables for patient taking atypical antipsychotics provided by the CEAF pharmacy in the state of Minas Gerais, 2017-2018 ${ }^{15}$

\begin{tabular}{|c|c|c|c|}
\hline Variables & Coefficient & Standard error & $\mathrm{p}$ - value \\
\hline Constant & 0.597 & 0.079 & 0.000 \\
\hline \multicolumn{4}{|l|}{ Income } \\
\hline Over $8 x$ /up to $4 x$ the minimum salary & 0.128 & 0.048 & 0.008 \\
\hline \multicolumn{4}{|l|}{ Labor activity } \\
\hline Employed/unemployed & 0.122 & 0.031 & 0.000 \\
\hline \multicolumn{4}{|l|}{ Comorbid diseases } \\
\hline None/two or more & 0.069 & 0.031 & 0.026 \\
\hline \multicolumn{4}{|l|}{ Psychoactive substance use } \\
\hline Never/former or current user & 0.102 & 0.046 & 0.027 \\
\hline \multicolumn{4}{|l|}{ Suicide attempts } \\
\hline None/ three or more & 0.157 & 0.032 & 0.000 \\
\hline \multicolumn{4}{|l|}{ Medicine } \\
\hline Clozapine/ziprasidone & 0.113 & 0.038 & 0.003 \\
\hline Clozapine/risperidone & 0.110 & 0.043 & 0.011 \\
\hline Clozapine/quetiapine & 0.113 & 0.038 & 0.003 \\
\hline Clozapine/olanzapine & 0.070 & 0.034 & 0.040 \\
\hline
\end{tabular}

CEAF = Componente Especializado da Assistência Farmacêutica (Specialized Component of Pharmaceutical Service).

among patients with psychotic disorders is high, and Wilson \& Cadet $^{26}$ believe that the rate may be up to twice as high as that of the general population.

Among our sample, $34.5 \%$ had attempted suicide at least once. Suicide attempts among patients with psychotic disorders is a matter of concern, since it adversely affects HRQoL. ${ }^{24,27}$ In the general population, suicide attempts are around 1\%; among schizophrenic patients, this rate can reach $50 \%$. ${ }^{28}$

In this study, $50.2 \%$ of the patients reported at least one comorbidity. The incidence of diseases, such as diabetes and cardiovascular disease, in patients with mental disorders is high and may be twice as high as that of the general population. ${ }^{29}$

Of this study's total sample, $53.3 \%$ currently use or have used CAPS/CERSAM for medical visits, group activities, or hospitalization. These patients arrive at CAPS/CERSAM units through self-referral or referral from other health services and, according to a study conducted in Belo Horizonte, their mean stay is 7.7 months. ${ }^{30}$

Overall, more than half of our sample reported no problems in the EQ-5D-3L dimensions mobility, self-care, usual activities, and pain/discomfort dimensions. On the other hand, $69.7 \%$ of the sample reported moderate or extreme problems with anxiety and depression, which is consistent with other studies. ${ }^{29,36}$

Clozapine users more frequently reported "no problems" for the EQ-5D-3L dimensions mobility, self-care, usual activities, and pain/discomfort, although in the anxiety and depression domain, quetiapine users reported the fewest problems. Clozapine has a lower incidence of extrapyramidal effects than other atypical antipsychotics due to its low affinity for D2 receptors. ${ }^{31}$ Quetiapine, however, has a greater affinity for 5 -HT2 receptors, ${ }^{5}$ which improves depressive symptoms and could partly explain the HRQoL results.

The percentage of SCHEEA project patients who reported moderate or extreme problems was higher in all dimensions than in the statewide sample of Andrade \& Noronha, ${ }^{10}$ which shows that patients on atypical antipsychotics have greater impairment in mobility, self-care, habitual activities, and anxiety/depression than other individuals. Since only the pain/discomfort dimension responses were similar in both groups, it can be concluded that patients on atypical antipsychotics have no more self-perceived pain and discomfort than the general population.

The participants'EQ-5D-3L responses were used to calculate utility scores, which reflect different health states. We compared the estimated values from the statewide population with those of our sample. The mean utility score for patients with psychotic disorders was 0.664 (SD: $0.232)$. The clozapine group had the highest mean utility score of any atypical antipsychotic. ${ }^{32,33}$ One factor in this result is the decrease in suicide attempts in patients unresponsive to other treatments. ${ }^{34}$ Another factor is that clozapine users have lower readmission rates than conventional antipsychotic treatments. Significantly higher readmission rates were found in patients who received conventional antipsychotics than clozapine users. ${ }^{33,35}$ Another relevant finding was lower illicit psychoactive substance use in the clozapine group than in the other groups. Clozapine also has a lower likelihood of extrapyramidal effects than the other antipsychotics. ${ }^{31}$

Variables such as gender, age, education level, marital status, and race were not associated with HRQoL in our sample, unlike the results Souza \& Coutinho's literature review. ${ }^{36}$ However other variables, such as employment, 
comorbidity, illicit psychoactive substance use, and suicide attempts were associated with HRQoL.

Employment directly affects HRQoL since feelings of competence contribute to mental health. ${ }^{37,38}$ Given that patients with mental disorders are generally unemployed, they have low incomes and do not have the resources to meet their daily needs. Thus, they are concerned with the future, feel dependent, and have difficulties dealing with personal finances, which contribute to low HRQoL. ${ }^{36,39}$

Patients with mental disorders can have other chronic diseases, as was the case in $50.2 \%$ of our sample. The most commonly reported diseases were hypertension, diabetes, and dyslipidemia, which could have negatively affected utility scores. In fact, the more chronic diseases, the more significant the impact on HRQoL. ${ }^{22,38}$

Our results indicate that illicit psychoactive substance use is adversely associated with HRQoL. This could be due to the fact that these substances have a considerable impact on treatment, such as poor response and noncompliance, which hinders patient recovery. ${ }^{40}$

According to the multiple linear regression model, variables that were significantly related to higher utility scores included: income at least eight times the federal minimum salary, employment, no illicit psychoactive substance use, no suicide attempts, no comorbidities, and clozapine use. These variables should be taken into account when developing mental health policies. Psychoactive substance use should be reduced in the general population, since it is related to the onset of psychosis ${ }^{23}$ and poor HRQoL. ${ }^{40}$ Proper education and training must be provided to patients with mental disorders so they can enter the labor market. ${ }^{37}$

Regarding the Clinical Protocols and Therapeutic Guidelines reported in this paper, patient-specific situations for using clozapine should be evaluated, such as patients with a history of hospital readmissions and current users of illicit psychoactive substances. ${ }^{11-13}$ Such evaluations are already performed in patients with a history of suicide attempts, those with significant tardive dyskinesia, and those unresponsive to other antipsychotics (for whom the protocol already recommends clozapine). ${ }^{11-13}$

Although the sample was calculated at 71 patients for each drug group, the clozapine and risperidone groups only had 65 and 45 patients, respectively. To avoid affecting the direction of results, the associations between QoL and sociodemographic, behavioral, and clinical variables should be carefully evaluated. This study did not include patients with mental disorders who are not taking antipsychotics. Furthermore, cross-sectional studies are insufficient to explore causal connections among variables.

In conclusion, clozapine users were more likely to report "no problems" in the mobility, self-care, usual activities, and pain/discomfort dimensions than users of olanzapine, quetiapine, risperidone, and ziprasidone. The drug with the best results for the anxiety/depression dimension was quetiapine.

We found that sociodemographic, clinical, and behavioral variables are associated with utility scores. Thus, individuals with psychotic disorders who are unemployed, use illicit psychoactive substances, have already attempted suicide, and have comorbid diseases have worse
HRQoL than other patients. Clozapine use was positively associated with HRQoL.

\section{Acknowledgements}

This study is a result of the first author's master's dissertation. The project was supported directly or indirectly by Coordenação de Aperfeiçoamento de Pessoal de Nível Superior (CAPES), Conselho Nacional de Desenvolvimento Científico e Tecnológico (CNPq), and Fundação de Amparo à Pesquisa do Estado de Minas Gerais (FAPEMIG).

\section{Disclosure}

The authors report no conflicts of interest.

\section{References}

1 The World Health Organization quality of life assessment (WHOQOL): development and general psychometric properties. Soc Sci Med. 1998;46:1569-85.

2 Karimi M, Brazier J. Health, health-related quality of life, and quality of life: what is the difference? Pharmacoeconomics. 2016;34:645-9.

3 Patrick DL, Erickson P. Health status and health policy: quality of life in health care evaluation and resource allocation. New York: Oxford University Press; 1993.

4 Kao CC, Huang HM. A comparison of the quality of life of patients with schizophrenia in daycare and homecare settings. J Nurs Res. 2014;22:126-35.

5 Falkai P, Wobrock T, Lieberman J, Glenthoj B, Gattaz WF, Möller HJ. Diretrizes da Federação Mundial das Sociedades de Psiquiatria Biológica para o tratamento biológico da esquizofrenia. Parte 1: tratamento agudo. Rev Psiquiatr Clin. 2006;33(Supll 1): 7-64.

6 Drake RE, Green Al, Mueser KT, Goldman HH. The history of community mental health treatment and rehabilitation for persons with severe mental illness. Community Ment Health J. 2003;39:427-40.

7 Druss BG, Chwastiak L, Kern J, Parks JJ, Ward MC, Raney LE. Psychiatry's role in improving the physical health of patients with serious mental illness: a report from the American Psychiatric Association. Psychiatr Serv. 2018;69:254-6.

8 Ward MC, Druss BG. Treatment considerations in severe mental illness: caring for the whole patient. JAMA Psychiatry. 2019;76:759-60.

9 Ciconelli RMTradução para o português e validação do questionário genérico de avaliação de qualidade de vida Medical Outcomes Study 36-Item Short-Form Health Survey (SF-36) [dissertation]. São Paulo: Universidade Federal de São Paulo; 1997.

10 Viegas Andrade M, Noronha K, Kind P, Maia AC, Miranda de Menezes R, De Barros Reis C, et al. Societal preferences for EQ-5D health states from a Brazilian population survey. Value Health Reg Issues. 2013;2:405-12.

11 Brasil, Ministério da Saúde. Portaria N ${ }^{\circ} 364$, de 9 de abril de 2013. Diário Oficial da União, 31 de outubro de 2002. Protocolo clínico e diretrizes terapêuticas - esquizofrenia. Brasília: Ministério da Saúde; 2013.

12 Brasil, Ministério da Saúde. Portaria $N^{\circ} 1203$, de 4 de novembro DE 2014. Diário Oficial da União, 5 de novembro de 2014. Protocolo clínico e diretrizes terapêuticas do transtorno esquizoafetivo.Brasília: Ministério da Saúde; 2014.

13 Brasil, Ministério da Saúde. Portaria N 315, de 30 de março de 2016. Diário Oficial da União, 30 de março de 2016. Protocolo clínico e diretrizes terapêuticas do transtorno afetivo bipolar do tipo I Brasília: Ministério da Saúde; 2016.

14 Berlim MT, Fleck M. "Quality of life": a brand new concept for research and practice in psychiatry. Braz J Psychiatry. 2003;25: 249-52.

15 SCHEEA Project. Avaliação dos aspectos econômicos e de efetividade em esquizofrenia [research report]. Belo Horizonte: Faculdade de Farmácia, UFMG; 2018. 
16 Santos M, Cintra MA, Monteiro AL, Santos B, Gusmao-Filho F, Andrade MV, et al. Brazilian valuation of EQ-5D-3L health states: results from a saturation study. Med Decis Making. 2016;36:253-63.

17 EuroQol Research Foundation. EQ-5D-5L user guide. Basic information on how to use the EQ-5D-5L instrument [Internet]. Version 2.1. [cited $2015 \mathrm{Apr}$ ] https://www.google.com/url?sa=t\&rct=j\&q=\&esrc $=s \&$ source $=$ web\& $c d=1 \& v e d=2 a h U K E$ wjAk-qvubPpAhXD8qQKHaOnC PcQFjAAegQIBRAC\&url=https\%3A\%2F\%2Feuroqol.org\%2Fwp-con tent\%2Fuploads\%2F2019\%2F09\%2FEQ-5D-5L-English-User-Guide_ version-3.0-Sept-2019-secured.pdf\&usg=AOvVaw2y4RbfqpYQJ3Om Zc2190Vd.

18 Cardoso CS, Caiaffa WT, Bandeira M, Siqueira AL, Abreu MN, Fonseca JO. [Quality of life and occupational domain in schizophrenia: a gender comparison]. Cad Saude Publica. 2006;22:1303-14.

19 Chaves AC. Diferenças entre os sexos na esquizofrenia. Rev Bras Psiquiatr. 2000;22:21-2.

20 Kirkbride JB. Addressing ethnic inequalities in the pathways to care for psychosis. BMC Med. 2018;16:240.

21 Pinheiro TLS, Cazola LHO, Sales CM, de Andrade ARO. Fatores relacionados com as reinternações de portadores de esquizofrenia. Cogitare Enferm. 2010;15:302-7.

22 Campolina AG, Dini PS, Ciconelli RM. Impacto da doença crônica na qualidade de vida de idosos da comunidade em São Paulo (SP, Brasil). Cienc Saude Coletiva. 2011;16:2919-25.

23 Barnett JH, Werners U, Secher SM, Hill KE, Brazil R, Masson K, et al. Substance use in a population-based clinic sample of people with first-episode psychosis. Br J Psychiatry. 2007;190:515-20.

24 Yan F, Xiang YT, Hou YZ, Ungvari GS, Dixon LB, Chan SS, et al. Suicide attempt and suicidal ideation and their associations with demographic and clinical correlates and quality of life in Chinese schizophrenia patients. Soc Psychiatry Psychiatr Epidemiol. 2013; 48:447-54.

25 de Araújo AA, de Araújo Dantas D, do Nascimento GG, Ribeiro SB, Chaves KM, de Lima Silva V, et al. Quality of life in patients with schizophrenia: the impact of socio-economic factors and adverse effects of atypical antipsychotics drugs. Psychiatr Q. 2014;85:357-67.

26 Wilson N, Cadet JL. Comorbid mood, psychosis, and marijuana abuse disorders: a theoretical review. J Addict Dis. 2009;28:309-19.

27 Alves Vde M, Francisco LC, Belo FM, de-Melo-Neto VL, Barros VG, Nardi AE. Evaluation of the quality of life and risk of suicide. Clinics (Sao Paulo). 2016;71:135-9.

28 Meltzer HY, Alphs L, Green Al, Altamura AC, Anand R, Bertoldi A, et al. Clozapine treatment for suicidality in schizophrenia: international suicide prevention trial (InterSePT). Arch Gen Psychiatry. 2003;60: 82-91.

29 Bent-Ennakhil N, Cécile Périer M, Sobocki P, Gothefors D, Johansson $G$, Milea D, et al. Incidence of cardiovascular diseases and type-2-diabetes mellitus in patients with psychiatric disorders. Nord J Psychiatry. 2018;72:455-61.

30 Oliveira GL, Caiaffa WT, Cherchiglia ML. Perfil dos pacientes atendidos e encaminhados a centros de saúde por um Centro de Referência à Saúde Mental em Belo Horizonte-MG. REME. 2007; 11:119-25.

31 Divac N, Prostran M, Jakovcevski I, Cerovac N. Second-generation antipsychotics and extrapyramidal adverse effects. Biomed Res Int. 2014;2014:656370.

32 Lewis SW, Davies L, Jones PB, Barnes TR, Murray RM, Kerwin R, et al. Randomised controlled trials of conventional antipsychotic versus new atypical drugs, and new atypical drugs versus clozapine, in people with schizophrenia responding poorly to, or intolerant of, current drug treatment. Health Technol Assess. 2006 May;10:iii-iv, ix-xi, 1-165.

33 Meltzer HY, Burnett S, Bastani B, Ramirez LF. Effects of six months of clozapine treatment on the quality of life of chronic schizophrenic patients. Hosp Community Psychiatry. 1990;41:892-7.

34 Meltzer HY, Okayli G. Reduction of suicidality during clozapine treatment of neuroleptic-resistant schizophrenia: impact on risk-benefit assessment. Am J Psychiatry. 1995;152:183-90.

35 Essock SM, Hargreaves WA, Covell NH, Goethe J. Clozapine's effectiveness for patients in state hospitals: results from a randomized trial. Psychopharmacol Bull. 1996;32:683-97.

36 de Souza LA, Coutinho ESF. Fatores associados à qualidade de vida de pacientes com esquizofrenia. Braz J Psychiatry. 2006; 28:50-8.

37 Argentzell E, Hakansson C, Eklund M. Experience of meaning in everyday occupations among unemployed people with severe mental illness. Scand J Occup Ther. 2012;19:49-58.

38 Zimmermann IR, Silva MT, Galvao TF, Pereira MG. Health-related quality of life and self-reported long-term conditions: a populationbased survey. Braz J Psychiatry. 2017;39:62-8.

39 Bengstsson-Tops A, Hansson L. Subjective quality of life in schizophrenic patients living in the community. Relationship to clinical and social characteristics. Eur Psychiatry. 1999;14:256-63.

40 Weiss KA, Smith TE, Hull JW, Piper AC, Huppert JD. Predictors of risk of nonadherence in outpatients with schizophrenia and other psychotic disorders. Schizophr Bull. 2002;28:341-9. 